\title{
Analysis of Errors Made by Iraqi University Students in the Area of English Relativization System
}

\author{
Abbas Naethel Naama \\ Department of English, Al-Nisour University College, Baghdad, Republic of Iraq \\ prof.abbas23@gmail.com
}

DOI: https://doi.org/10.36892/ijlls.v2i1.194

$\begin{array}{ll}\begin{array}{l}\text { Received: } \\ \text { 06/02/2020 }\end{array} & \text { Abstract } \\ & \text { This study aims at giving an account of an analysis of errors made by Iraqi } \\ \text { Accepted: } & \text { miversity students in the area of English Relativization system. It focuses } \\ \text { 18/03/2020 } & \text { mainly on dealing with the investigation of the syntactic errors committed } \\ & \text { fy Iraqi students in English relative clause. This causes a major problem } \\ \text { Keywords: } & \text { from the students' interlingual and intralingual strategies. This also } \\ \text { Error Analysis; Errors; } & \text { indicates that the university students seem to depend on the target } \\ \text { Taxonomy of Errors; } & \text { language (TL) system rather than on that of the native language (NL). The } \\ \text { Relativization } & \text { technique used is an error analysis which Wilkins (1972) highlights its } \\ & \text { value in giving "greater understandings of the difficulties that learners } \\ & \text { face, and will perhaps assist in the development of pedagogic strategies." } \\ & \text { (p. 206). After analyzing and interpreting the errors made in the 100 } \\ \text { students' compositions, some recommendations are given. }\end{array}$

\section{INTRODUCTION}

The last two decades have witnessed an increasing interest in second language learning. One of the major interesting developments is "Error Analysis" which has been discussed extensively by linguists, psychologists, sociologists, and educationalists.

There have been various ways of looking at the significance of errors, Chau (1975) claims that errors are longer considered as undesirable and avoidable short comings in the learners' performance, but as indispensable devices he uses to test his hypotheses about the language he is learning. Selinker (1974) uses the term "interlanguage" which emphasizes the structurally intermediate status between the mother tongue and the target constructive features of no learner's system language. Chau also sees errors as language learning", while Jain (1974) regards errors as "an essential condition of learning"; Corder (1981) also makes the insightful observation that learner's errors are indicative of the rules he is using and of the strategies in which a second language is learned. He (1981) points out those three aspects of error significance:

First the learner, in that they tell him how far towards the goal the learner has progressed and, consequently, what remains for him to learn. Second, they provide evidence to the researcher of how language is learnt or acquired, what strategies the learner is employing in his discovery of the language. Thirdly, they are indispensable to the learner himself because the making of errors can be regarded as a device the learner uses in order to learn. (p. 11) 
These fresh ways of looking at errors as proposed by above-mentioned linguists and researchers show that errors in learning are significant. It has also been noticed that errors are not completely caused by differences between the learner's mother tongue and the target language. Another value analysis that has been emphasized by Wilkins (1972) refers to better understanding on the part of teachers of the difficulties which face the learners. Consequently, the researcher maintains that studying learners' errors has significant phases. First, a pedagogical phase which indicates understanding the nature of errors before reducing them. Here Corder (1973) points out that "errors provide feedback to the teacher about his materials and techniques, whereas the theoretical phase shows the relevance of learners, errors in reconstructing their language which is, itself very valuable to an understanding of the language learning."(p.213). This significant idea has been discussed by Al-Azabi (1967), Bright and McGregor (1981), Musonah (2014) and Fengjie, Jia, and Hongyi (2016)).

\section{The Problem}

Throughout the researcher's teaching experience, he has found that students at university level often encounter various difficulties in the English relativization system. Because of the complexity of this system, and the many differences in meaning, form, and structure between English and Arabic relativization system, students are liable to find difficulties in choosing the correct forms or using different forms of this system correctly.

\section{Aim of the Study}

This study is designed to identify errors that Iraqi university students at the second year Dept. of English, Al-Nisour University College make in English relativization system and then try to give an explanation for such errors, and this study also aims at giving pedagogical suggestions for university instructors understanding errors in a more systematic way and arriving at some techniques that may help correct their students.

\section{Significance of the Study}

Since this study is trying to analyze errors made by Iraqi students at second university level, it is hoped that its findings will be of great value to both university instructors and learners of English as a foreign language as well as provide textbook writers with information about difficult spots in the English relativization system for Iraqi learners.

\section{Limitations of the Study}

1. This study will mainly deal with the English relativization system as a syntactic category, and thus avoid any detailed analysis of the topic under research.

2. The language usually referred to the explanation of students' transfer errors is Modern Standard Arabic since it is officially used today in Arabic newspapers, radio, and T.V. newscasts, official meetings, conferences, and formal education and may thus cause interference. Thus, Colloquial Iraqi Arabic, though it may play a significant role, has been avoided.

3. For practical reasons the number of students tested was limited to 100 second-year students from the Department of English, Al-Nisour University College.

\section{THE RESEARCH PROCEDURE}

The researcher has opted to use composition technique of errors for the following reasons:

1. Students' compositions can have a range of examples of errors system. 
2. The use of translation instead of composition is bound encourage exaggerated, and therefore distorted, rate of interference errors.

3. The use of multiple-choice questions, on the other hand, is bound to be prejudiced by the researcher's own preconceptions of potential problematic spots in the area of English Relativization, Moreover; it is possible to overlook many interesting problematic areas. Besides, good multiple-choice test items are not easy to set and time-consuming.

4. The result of error analysis based on composition as an eliciting technique may later be made use of in constructing either translation which was used by Lee (2012) and Wongranu (2017) or a multiple-choice test whose results can complement those of the composition.

Consequently, second-year students from department of English, Al-Nisour University College have been randomly chosen, 100 compositions written by second year students elicited for the purpose of error of analysis. Really the researcher read each composition and errors in the relativization system were marked.

\section{RESULTS AND DISCUSSION}

The total of (535) errors have been identified. A close examination of these errors has shown that they fall into six major syntactic types. Table (I) below reports the taxonomy and frequency of these errors.

Table. Taxonomy of Errors

\begin{tabular}{lcc}
\hline Type of Errors & Frequency of Errors & Percentage \\
\hline I. Retention of a Pronominal & 140 & 16 \\
\hline II. Inappropriate Relative Pronouns & 70 & 13 \\
\hline III. Wrong Case of Relative Pronouns & 95 & 18 \\
\hline IV. Misplaced Relative Clauses & 85 & 16 \\
\hline V. A Non-Relative Clause after (That). & 65 & 13 \\
\hline VI. Inappropriate Relative Pronoun & 80 & 15 \\
after a preposition & & \\
\hline
\end{tabular}

\section{Interpretation of Errors}

It is a well-known fact among these involved in error analysis that the interpretation of source(s) of error is notorious for being complicated, hazardous, and tentative. Yet a serious and systematic look at interpretation can help reveal lots of interesting aspects of the process of language learning. Since error analysis is normally concerned with group errors rather than with individual errors, any error with less than three occurrences has been ignored as being insignificant. Thus, no attempt has been made to interpret such errors. A cursory look at the remaining errors in this category lies in different kinds of positions; subjects, etc.

\section{Error Type I: Retention of a Pronominal in a Relativized Slot}

This category indicates that the subjects, having relativized noun phrase, retained a pronominal in the position of that noun phase. Thus, such sentences as the following were given:

1. There are many poets who wrote them.

2. The student who I met her in class is friendly.

3. He can get good friends who they love him.

4. Shatt-al Arab which many giant ships cross it is very nice 
5. My room contains a wheel chair and a table, which they look nice.

6. The husband who chooses his wife he must convince her.

7. The things, which I am fond of them, are reading and writing.

In such sentences, the subjects retained the pronouns (them, her, it, they, he), in slots where they should have been omitted. Thus, these are ungrammatical in English, though they convey a certain meaning. A native speaker of English would utter all the sentences with personal pronouns; it seems clear that the total number of errors in this category is 140: it is about $16 \%$. At first look, this type of errors seems to result from interference of the learner's native tongue: in this case Arabic. Such errors are indicative of the learner's reliance on the structures of the first language. For instance,

8. These factors destroy the family and make people whom their society breaks the laws.

9. The first thing I like to describe is my room, which its color is beige.

10. I share the room with two students whom their moods are changeable.

It seems clear that a native speaker of English would not make such errors. He/she would use who (m) with nouns that have these semantic features (+ animate, + human) while (which) is used with nouns having the feature (human). Hence, (which) should have been used in $(8,10)$ and (who) in (9). In $(8,10)$, the relative pronouns (whom) and (which) were also mistakenly selected rather than (whose).

A careful examination of errors in this category clearly shows interference from LI of the learners' i.e., Arabic in this case. The avoidance of such errors is supplied by such sentences as (9-10) above. It is familiar that English native speakers tend to use (who) for animate nouns, regardless of the gender of the relativization and (which) as nominal since English relative pronouns are not sensitive to gender. However, Arabic native speakers tend to generate deviant structures where the relative pronoun agrees with its antecedent in gender since the Arabic relative pronouns /alaði/ and /alati/ are sensitive not only to number and case , but also to gender; /alati/ replace singular feminine nouns like /al-mar?ata/ 'the woman' as well as plural inanimate referents like /al-madaaris/ 'the schools'; and /al-aði/ refers to a singular masculine noun like /al-sadiiq/ 'the friend' Hence, the errors exposed in (9-10), where the nominal woman, and friend were analyzed as feminine and masculine respectively.

An analysis of the above sample errors indicates that the transfer errors occurred can possibly be ascribed to teaching techniques. Teachers of English in secondary schools tend to use the translation of Arabic pronoun /alati/ (which) and /alaði/ (who). This tendency is, as a matter of fact, misleading since the Arabic /alati/ covers more semantic domains than the English pronoun (which) does.

One can also notice that the negative transfer or Arabic interference comes from erroneous sentences like (8-10) given above. Iraqi Arab speakers do not familiarize with having a relative pronoun equivalent to (whose) in English; they usually express the concept of possession by means of a relative pronoun like /alaði/ and /alati/ and a pronominal possessive affix to the noun which is co-referential with the head noun modified by the whole relative clause. This fact, therefore, declares why Iraqi Arab learners of English erroneously use a possessive adjective or pronoun, in addition to an English relative pronoun in cases like (8-10). This finding is also reported in Kharma's $(1985,1987)$ studies of Arabic learners of English in Kuwait. As expected, such a tendency will be continuously checked by teachers of English, who will keep telling their learners to correctly use (who) and (which) in English. Thus, with more and more learning and practice of English, Iraqi Arab learners will learn to use (who) and (which) in English. 


\section{Error Type III: Wrong Use of Relative Pronouns}

This type of errors contains relative clauses in which pronouns do not agree in case with relativized nominal. This category which covers 95 errors scores $18 \%$. For example, in:

11. He can get a good friend whom loves him.

12. The seeds of evil of human beings, whom try to avoid ail people.

The pronoun (whom) is used in a subject slot. Such a slot should have been filled by a relative pronoun whose case is nominative. Therefore (who) not (whom) must have been used in the above two examples. This tendency on the part of Arabic learners of English to use whom instead of who comes from the wrong Arabic translation to English who into /alaði/ /alati/ is due to insufficient learning or lack of attention on part of the learner. It is also that inadequate teaching technique is another contributing factor.

Rule-condition is another source of such errors. This factor refers to observe the restrictions or conditions on relative clause constructions. These obviously indicate Iraqi Arab learners' failure to realize the case distinctions between (who) and (whom) in English, as no such distinctions are made in relative pronouns in Arabic. This failure could also be attributed to the fact that who very frequently substitutes for whom.

Thus, having realized such a substitution, Iraqis tend to place (who) by (whom) even in a subject slot, producing deviant structures. Kharma (1985) reports that the same reason for such errors. He also supplies another reason, reflection for "case" and other categories in English is very limited and this gives rise to several kinds of errors... because foreign learners of English who come from communities with highly inflected languages, such Arabic, tend to disregard the few reflections that have survived in present-day English. This is a phenomenon quite noticeable in the English of Arabs. However, one can claim that the attribution of more than one source to an error creates a perplexing situation for linguists who attempt to account for every single error by means of one and only one source. This means that linguists cannot always be sure of the source lying behind a given error. Consequently, Khalil (1985) stated "multiple source of error possesses an inevitable problem for researchers who try to compare and validate the findings of the different error analysis that focus on learning with the same NL (i.e. learner's native language) background (p. 25).

\section{Error Type IV: Misplaced Relative Clauses}

This type of error is composed of sentences in which relative clauses are put in appropriate positions. This category, which scores $16 \%$, covers 85 erroneous sentences. This is indicated by the following examples:

13. The several factors it has which are very important for the life.

14. The incompatible habits between them are important that the couple must behave at the same habits.

15. The tourist place is in Iraq which 1 went to it.

16. Marriage is the sacred bond that joined husband with wife.

17. The pictures of the mountains and higher streets are attractive that took my attention.

It seems clear that the above mentioned relative pronouns in (13-17) appeared in a position, which violates the normal order of an antecedent and its modifying relative clause in English. It is familiar the relative clause is placed immediately after its antecedent. As a result, the clause should have been positioned after the antecedents "the several factors", "the incompatible habits", "the tourist place", and "the pictures of mountains" and "higher streets". 
The ungrammaticality as (14-15) stems from another factor. It is "communicative effect". The relative clause in these positions distort communication since the sentences have more than one reading, particularly sentence (15):

15. A. The tourist place, which I went to, is in Iraq.

15 . B. The tourist place is in Iraq where I went.

Thus, the reader gets confused with respect to the antecedent of the relative clause. Is it "tourist place" or "Iraq"? An analysis of the above sample errors indicates that the source of such errors may be indirectly related to differences in motivation. This factor that the learners need to communicate for exceeding their need to produce well-formed sentences. This is, as a matter of fact, evidenced by the length of the composition those learners had written. A large number of them consisted of more than two pages replete with meaningful structures. All the previous structures save for (16-17) communicate a lot of information. This interpretation is consonant with Kharma (1985) who assumes that the errors committed are "errors of form rather than use and that they do not seriously affect communication" (p.340).

\section{Error Type V: A Non-relative Clause After the Relative Pronoun (That)}

This type of errors, which covers 65 , scores about $13 \%$. This category includes erroneous constructions in which the relative pronoun (that) is wrongly followed by a non-relative clause as exemplified in such cases:

18. I want to tell you very pleasant new that I have succeeded in my lessons.

19. My town also has the advantage of industry to be educational centre that it has one of the most famous universities in the world.

20. We can learn from the wisdom that it is not difficult.

21 . The stack contains all my books and magazines that they must be kept dean.

As table one shows, the errors in this category have to do with a non-relative clause after the relative pronoun (that). The ill for madness of such sentences could be attributed to the use of a complement having both a subject and a predicate after (that) generated by analogy with complements in cases like:

22. I believe that John loves Mary

That seems to be analyzed by the students as a complementizer or a connector than a relative clause. This type of error seems to result from overgeneralization which is the process where by a syntactic rule or structures in the target language are extended to an environment in which to the learner, it could logically apply, but it does not. Selinker, (1974) assumed that. English has a dependent clause starting with the complementizer or connector that functions as a subject or an object complement as illustrated in (23-24).

23. That John's theory is verified is interesting.

24. Mary thinks that John's theory is verified.

In such cases, (that-clause) is composed of that followed by a subject and a predicate. The Iraqi Arab students seem to have overgeneralized this structure of that-clauses to environments, in which it does not apply, producing ungrammatical sentences like (25-27):

25. I want to tell you very pleasant news that I have succeeded in my lessons.

26. We can learn from the wisdom that it is not difficult

27. This stuck contains all my books and magazines that they must be kept clean.

One might claim that Iraqi Arab learners have most possibly taken the relative pronoun (that) for the connector (that), thus generating such deviant structures. It is also possible that teaching techniques could be a factor behind this strategy. Teachers may expose that-clauses at one time and relative clauses where that is used at another time without making any comparison between 
the two completely different structures to each other. As a result, these Iraqi learners are liable to overgeneralize the structure of that-clauses to all other structures where (that) surfaces.

\section{Error Type Vi: Inappropriate Relative Pronoun Following a Preposition}

This type of errors, which comes at the third number of the total errors, it scores $15 \%$. This category is made up of ungrammatical sentences having a preposition, which is followed by an incorrect relative pronoun as is illustrated in sentences like (28-29).

28. The students with who 1 talked in the class are helpful.

29. Marriage is the sacred bond to that joined husband and wife.

An examination of such errors shows that the ungrammaticality of such cases as (28) stems from the fact that a relative pronoun whose case is non-accusative or non-objective cannot have co-occurrence with a sentences like (29) is attributable to the likelihood of the co-occurrence of the relative pronoun that with a preceding preposition. Based on such cases, one can claim that such set of erroneous sentences is attributed to learners' failure to observe rule-conditions in the target language include:

30. The students with who I talked in the class are helpful.

31. The girl to who I had given her a gift is the one that I like most.

32. The wall has one window from that I can see a beautiful side from our university.

33. The marriage is the scared bond to that joined husband and wife.

Cases like (30-33) violate the condition placed upon to form or case of the relative pronoun whose antecedent is personal when a preposition precedes it. Such cases cannot be ascribed to Arabic interference because in Arabic a preposition cannot precede a relative pronoun, but rather follows the relative clause i.e. it is postponed. Likewise, erroneous sentences like (32-33) indicate that Iraqis learning English violate the condition that blocks the use of that when a preposition must either be postponed, or (which) or (whom) must be used depending upon whether the antecedent is personal or non-personal. Last but not the least, the position of a relative clause in relation to its antecedent is a case in point. Though sentences like (16-26) show that the students know how to build a relative clause, they, as the researcher has stated earlier, act contrary to the condition which entails that a relative clause be placed very near to its antecedent. Such an error cannot also be ascribed to Arabic interference on the ground that Arabic, like in English; a relative clause should follow its antecedent.

\section{CONCLUSION}

The conclusion of the study is summarized into these points:

1. Analysis of text results has revealed that after nine years of learning English, second-year students at university level still make different kinds of errors in the English relativization system. This could at least partly attribute to the teaching textbooks the students use throughout nine years of study.

2. An examination of the gravity of errors shows that (26\%) of the errors in table (I) are of the category I. (140) out of (535) errors belong to this type of errors. Special attention needs to be paid to this category when teaching English to Iraqi students. Such an attention needs to be reflected in the number of drills and exercises dealing with such category. On the other hand, wrong case of relative pronouns-errors make up about $18 \%$ of the total number of errors; (95) errors out of (535) errors belong to this category. Consequently, teachers and textbook writers should pay attention to this category of errors. 
3. A cursory look at the interpretation of errors shows that mother-tongue interference seems to play but a little role in the total number of errors made by students. This, however, is not an unexpected result since the topic under investigation, viz., the English relativization system, falls within syntactic domain of the language. Many other contrastive studies have shown that $\mathrm{LI}$ (native language) interference is less in the area of syntax and greater in the area of phonology.

4. Another possible conclusion is related to language learning that learners tend to depend on their mother tongue if they are not familiar with the linguistic system of the target language. However as their proficiency increases in the target language, they rely more on their developing knowledge of the TL than on the NL. Their reliance on the TL is implied by the Iraqis' tendency to overgeneralize its rules.

5. It is possible that Iraqi learners do not know the difference in case between the forms (who) and (whom), nominative and accusative respectively. Nor do they know that a syntactic relationship exists between a relative pronoun and a noun phrase replaced by such a pronoun. 6. The last finding is the learner's tendency to simplify that relativization system of the TL. What the researcher means is that learners try to avoid the use of relative clause where possible.

\section{RECOMMENDATIONS}

The following recommendations can be presented:

1. A text analysis of textbooks used for the teaching of English in Iraq will shed light on the number and type of exercises used to teach the English in relativization system. This is a necessary step in any attempt towards improvement. Consequently, such as a text-analysis is suggested.

2. The typology and gravity of errors arrived at in this study could also be compared with similar studies on errors made by children acquiring English as their mother tongue/and or errors made by learners with different language background. This will help to shed light on the native and strategies of learning language whether a second language or a first language.

3. An error analysis in the area of English relativization system for fourth-year university students would reveal interesting results. It would show the degree of command of Englishdepartment university students at the end of their university program. This would help in the evaluation of courses, teaching materials and teaching techniques at the college or university level. Comparing results of the present study conduction on second-year students with those of the study proposed here conducted on fourth year students would make an interesting and worthwhile developmental study.

4. The researcher would like to propose to train both Iraqi undergraduate students and university instructors to use e-learning technique which has been suggested by Laachir, (2019) in order to be competent university students and instructors in Iraq. Moreover, also to keep them up-to-date with the latest learning techniques in EFL.

\section{REFERENCES}

Al-Azabi, Y. (1967). A sector analysis of modern written Arabic with implications for teaching English to Arab students. Ed. Diss. Columbia University.

Bright, J. A. and G. P. McGregor (1981) .Teaching English as a second Language. (11th Ed.) U.K.: Longman Group Ltd.

Chau, T. T. (1975). The frequency of errors is proportional to the degree of learning difficulty. IRAL XIIII(2),120-135. 
Corder, S. P. (1973). Introducing applied linguistics. Harmonthsworth: Penguin Books Inc.

Corder, S.P (1974). The significance of learner's errors. In Jack C. Richard's (Ed.). Error analysis: Perspectives on second language acquisition. London: Longman Group Limited, 1974,( pp.55-67).

Corder, S.P (1981). Error analysis and interlanguage. Oxford: Oxford University Press.

Corder, S.P. (1974). Arab students: Problems with the English relative clause. IRAL, 24(3), 257266.

Fengjie, LI, Ren Jia, Hongyi ,Z. , Z.(2016). Grammatical mistakes in college English writing problem analysis, reasons , and solutions. International Journal of Applied Linguistics and Translation .2(3), 20-28.

Jain, M. P. (1974). Error analysis: source, cause, and significance. In Jack C. Richard's (Ed.). Error analysis: Perspectives on second language acquisition. London: Longman Group Ltd. 1974,( pp.189-215).

Khalil, A. (1985). Interlingual errors in Arab freshman English compositions. Bethlehem University Journal /4,8-31.

Kharma, N.N. (1985). Arab students and the English relative clause. Arab Journal for the Humanities, 19(5), 328-341.

Laachir, A. (2019). The use of e-learning in foreign language learning: A Case Study of Undergraduate EFL Students. International Journal of Language and Literary Studies, 1(3), 30-42. https://doi.org/10.36892/ijlls.v1i3.79

Lee , E.T (2012). Collaborative learning in translating a travel guide: A case study. Translation Journal 16(3), 23-34.

Musonah , A.(2014). An Analysis on students' errors in using relative pronouns (Who, Whom, Which, Whose): A case study in the second year of Fatahillah senior high Seymour school. Jakarta : Tianjin University Press .

Selinker, L. (1974). Interlanguage . In Jack C. Richard' (Ed.). Error analysis: Perspectives on second language acquisition. London: Longman Group Ltd. 1974: (pp.31-57).

Wilkins, D. (1972). Linguistics in language teaching. London: Edward Arnold Ltd.

Wongranu , P. (2017) . Errors in translation made by English major students: A study on types and causes'. Kasetsart Journal of Social Sciences ,38(7), 117-122.

\section{AUTHOR'S BIO:}

Dr. Abbas Naethel Naama has a Ph.D. in Linguistics \& Translation Studies. He has been working in the field of linguistics for almost 35 Yrs. covering all aspects of language research starting from ELT to translation. He has various papers and research articles related to linguistics as well as translation including error analysis and more. He has been holding various academic positions such as Dean of Arts Faculty, Civilization Private University, Yemen, HOD of English department in Arts College, Basrah University, Iraq and now as HOD of English department, Al-Nisour University College, Iraq. 